\title{
A oralidade presente em $U m$ passeio pela cidade do Rio de Janeiro, de Joaquim Manuel de Macedo
}

\author{
Sheila Katiane Staudt
}

\begin{abstract}
Resumo: Este trabalho pretende analisar a obra quase Abstract: This research intends to analyze the almost desconhecida do autor de A moreninha Joaquim unknown book of $A$ Moreninha's author: Joaquim Manuel de Macedo, intitulada Um passeio pela cidade Manuel de Macedo, entitled as Um passeio pela cidade do Rio de Janeiro no que diz respeito à oralidade do Rio de Janeiro concerning the signs of orality that presente neste livro de crônicas. As características appear in this book of chronicles. When telling stories próprias de um contador de histórias, no instante de about the public heritage of Rio de Janeiro, the peculiar narrar acontecimentos acerca do patrimônio público characteristic of a real storyteller comes out in this carioca ficam evidentes em sua travessia pela cidade, walk through the city, as well as the narrator's constant bem como a constante preocupação deste narrador para worry about the truth of his chronicles. As a theorical com a verdade narrada em suas crônicas. Para isso support we took the texts: $O$ tempo vivo da memória: foram utilizados como apoio teórico os textos: $O$ tempo ensaio de psicologia social, by Ecléa Bosi, $O$ tempo e a vivo da memória: ensaio de psicologia social, de Ecléa cidade, by Ana Luiza Rocha and Cornelia Eckert, Bosi, O tempo e a cidade, de Ana Luiza Rocha e Narrativas orais: uma poética da vida social, by Nei Cornelia Eckert, Narrativas orais: uma poética da vida Clara de Lima, among others.

social, de Nei Clara de Lima, entre outros.
\end{abstract}

Palavras-chave: oralidade; cidade; memória.

Keywords: orality; city; memory.

Ao estudarmos a obra quase desconhecida de Joaquim Manuel de Macedo, intitulada Um passeio pela cidade do Rio de Janeiro, de 1862, percebemos que o autor convida o leitor a passear pela capital do Império conhecendo, ao mesmo tempo, a história de seus principais monumentos e instituições. O cronista revela aspectos anedóticos e históricos da cidade entrelaçando a memória social e a história oficial em seu relato, enriquecendo sobremaneira sua narrativa.

A fim de ilustrar estas passagens e caracterizar o contador de histórias nesta obra, tentaremos perceber as estratégias utilizadas por MACEDO (1862) ao mesclar história e memória retratando o patrimônio público carioca e suas singularidades aos seus companheiros de passeio.

\footnotetext{
*Mestranda em Literatura Brasileira na UFRGS. E-mail: shelex@ibest.com.br
} 
No primeiro capítulo, observaremos as marcas próprias de um contador de histórias, sua forma de narrar os relatos acerca dos locais visitados, bem como as estratégias utilizadas por MACEDO (1862) a fim de prender a atenção do leitor, seu ouvinte naquele momento.

No segundo capítulo, será enfatizada a questão da veracidade sobre os fatos ocorridos em sua narrativa. A preocupação em relatar ao seu acompanhante de passeio o acontecimento de maneira mais fiel possível é uma constante em sua travessia pela cidade. E, para que suas histórias possuam esta credibilidade por parte do seu público, o cronista faz uso de cartas, documentos, manuscritos, enfim, provas que sustentem suas assertivas reproduzindo, em parte ou integralmente, muitas delas em sua obra. Outro recurso por ele utilizado são as fontes orais, principalmente, as histórias ouvidas de um padre velho que lhe permitiu saber inúmeras curiosidades e lendas populares acerca da origem de diversos monumentos e edifícios cariocas, fatos estes sem registros escritos, mas resgatados da memória social da comunidade.

\section{Os traços de oralidade}

MACEDO (1862), ao explicar aos seus leitores o porquê de escrever suas crônicas sobre o Rio de Janeiro, afirma prestar um serviço ao país informando o quanto pudesse acerca dos edifícios, estabelecimentos públicos e instituições cariocas, como também das personalidades notáveis e usos e costumes do passado.

Por outro lado, o escritor critica o povo brasileiro, e, em especial, os cariocas por não conhecerem verdadeiramente sua cidade (então capital do Império), mas serem gabaritados no que se refere à Europa, fato este, segundo ele, favorecido pelo progresso:

\footnotetext{
Disse um escritor francês, cujo nome agora não me lembro, que entre os franceses são os parisienses os que conhecem menos Paris. No Brasil não se pode dizer coisa semelhante, porque os provincianos, como os cariocas, desconhecem do mesmo modo a nossa boa Sebastianópolis.

Se noutro tempo era grande essa antipatriótica falta de curiosidade, agora é muito pior: os paquetes a vapor e a facilidade das viagens ao velho mundo tiram-nos a vontade de passear o nosso, e é mais comum encontrar um fluminense que nos descreva as montanhas da Suíça e os jardins e palácios de Paris e Londres do que um outro que tenha perfeito conhecimento da história de algum dos nossos pobres edifícios, da crônica dos nossos conventos e de algumas das nossas romanescas igrejas solitárias, e até mesmo que nos fale com verdadeiro interesse dos sítios encantadores e das eminências majestosas que enchem de sublime poesia a capital do Brasil.

Hoje em dia uma viagem a Lisboa é coisa mais simples do que um passeio ao Corcovado. (MACEDO, 2004, p. 23)
}

Desta forma, o cronista revela sua inteira afinidade com o espírito romântico da época ao fazer apologia aos motivos nacionais em detrimento dos procedentes do estrangeiro. Ao criticar o total desconhecimento do brasileiro por sua terra, MACEDO (1862) traz um 
exemplo acerca dos parisienses, que agem de maneira idêntica a fim de persuadir seu companheiro de viagem, convidando-o a realizar um passeio totalmente novo e irrecusável, já que de fato as coisas da nossa própria cidade são pouco exploradas por seus verdadeiros habitantes.

Desde o início de seu passeio, o cronista adverte seu leitor de não seguir uma ordem ou regularidade em suas andanças pela cidade:

\begin{abstract}
Excluamos do nosso passeio toda a idéia de ordem ou sistema: regular os nossos passos, impor-nos uma direção e um caminho fora um erro lamentável que daria lugar a mil questões de precedência em que, sem dúvida, os frades Barbadinhos seriam os primeiros a fazer ouvir bem fundados protestos em nome da igreja de S. Sebastião.

Independência completa da cronologia! Um passeio cronológico obrigar-nos-ia a começar dando um salto do Pão de Açúcar ao morro do Castelo, e um salto desses somente com ligeireza e com as pernas dos volantins políticos se poderia dar. (MACEDO, 2004, p.25)
\end{abstract}

A cronologia é excluída de seus passeios revelando um trabalho similar ao da memória que recua ao passado e retorna ao presente sem uma ordenação prévia. De acordo com Ecléa Bosi (2003), “é importante respeitar os caminhos que os recordadores vão abrindo na sua evocação porque são o mapa afetivo da sua experiência e da experiência do seu grupo - no caso, até mesmo da sua cidade [...]" (BOSI, 2003, p.56). A advertência acerca do procedimento por ele utilizado ao contar as histórias do Rio de Janeiro deve, portanto, ser respeitada, visto que uma ordem em sua narrativa poderia afetar o trabalho de resgate desses acontecimentos advindos, em sua maioria, da memória popular.

Fenômenos sobrenaturais contados pelo povo acerca de inúmeros monumentos também fazem parte do repertório de Macedo. A história da construção da ermida de Nossa Senhora do Ó está repleta de acontecimentos inusitados que envolvem o leitor neste passeio singular pelo Rio de Janeiro. O cronista narra o seguinte:

Um dia, celebravam os carmelitas uma solenidade religiosa, a ermida estava cheia de devotos, e eis que de repente estala o teto que as paredes abandonam, e estas e aquele caem, abatem e esmagam um crescido número de indivíduos. [...] Um do povo inventou ou sonhou, alguns aperfeiçoaram o invento ou o sonho, e muitos acreditaram e foram transmitindo de pais a filhos e de filhos a netos uma segunda tradição a respeito da ermida de Nossa Senhora do Ó.

Eis aqui, pouco mais ou menos, o que diz a tradição popular [...] (MACEDO, 2004, p.70)

MACEDO (2004) relata em seguida a causa daquele desastre através de narrativas provenientes da tradição popular as quais trazem o elemento fantástico ao seu texto. Aquela história constitui-se de uma lenda acerca de dois jovens apaixonados - um ermitão e uma viúva - responsáveis pela construção da igreja. Os dois exigiram em troca a promessa de que, todos os anos, fossem acesas velas em seus túmulos. Contudo, no sétimo ano, esta promessa 
foi esquecida, ocorrendo então a catástrofe funesta atribuída às almas daqueles amantes que velavam a ermida de Nossa Senhora do Ó.

MACEDO (2004) conversa com o leitor sobre a opção de narrar casos advindos da oralidade, os quais são pouco valorizados pela maior parte da opinião pública:

[...] tradições como essas abundam nos arquivos da imaginação e da credulidade de todos os povos, e encontram-se em todas as nações.

Que mal faz perpetuá-las? São as poesias do povo, os velhos amam-nas, os meninos as aprendem de cor, os poetas as escutam cobiçosos, a terra da pátria se enfeita com elas.

Quem não gostar de um passeio assim dado, não passeie comigo.

E não zombem do povo, não. Não se riam da inocente credulidade do povo.

Há credulidades de sábios doutores que não ficam aquém da credulidade do povo. (MACEDO, 2004, p.73)

Percebemos através das opiniões de MACEDO (2004) suas concepções em relação às tradições populares e o valor dado aos ensinamentos que daquele meio advêm no instante em que ele equipara as crenças populares às crendices consideradas sábias. Desta forma, podemos constatar o apreço deste autor para com as narrativas orais e sua atitude impositiva de abraçar esta tradição em sua crônica.

Platão (1966), em seus diálogos, refletiu intensamente sobre a oralidade e a escrita, e assinalou uma gradual predominância desta sobre aquela. Através desta constatação, o filósofo sinalizava para a perda da memória da população num futuro vindouro.

LIMA (2003) assegura que os contos orais são portadores de atributos suficientes para serem considerados fontes primorosas de pesquisa e investigação por parte de historiadores e estudiosos em geral. "Condensando e entrelaçando crenças religiosas e moralidades, acontecimentos históricos e ficcionais, concepções de tempo e espaço, (as narrativas orais) constroem uma espécie de poética da vida social, por contarem eventos através de alegorias." (LIMA, 2003, p. 12-13)

Constituídos em grande parte pela poesia popular, como asseveram MACEDO (2004) e LIMA (2003), esses relatos e, até mesmo o passeio, tornam-se mais instigantes ao caminhante que começa a conhecer causos e histórias repletos de alegorias, contados pelo povo que testemunhou ou ouviu de outrem acontecimentos inusitados desses locais visitados.

Os ditos populares também fazem parte de suas crônicas e servem de inspiração ao autor que, a partir deles, cria novos ditados, os quais se aplicam a outras situações, ampliando o significado do primeiro:

Dizem que o oficial é quem faz o soldado. Asseguram os entendidos nas coisas militares que não há soldados maus nem covardes, quando são comandados por bons e intrépidos oficiais.

Eu creio que se pode dizer do clero o mesmo que se diz do exército.

São os bispos que fazem o clero. [...] (MACEDO, 2004, p. 265) 
Com isso, constatamos a presença da oralidade nestas crônicas de MACEDO (2004). A transcrição de ditados populares e a adaptação dos mesmos a contextos diversos mostra a ambivalência desta forma típica de expressão das crenças e hábitos oriundos da cultura popular. Neste instante, Macedo deixa transparecer seu lado anedótico, pois ao ressignificar o dito popular, ele responsabiliza o bispado pela instrução e exemplo ensinados ao clero.

Outra ocorrência dos ditados populares em suas crônicas, acontece no passeio pela igreja de São Pedro. A exemplo disso temos a passagem: "Diz um antigo anexim que se beijam as pedras por causa dos santos. Neste caso, porém, o anexim falhou, observou-se o contrário, e o tempo veio demonstrar que se venerava o santo por causa do bispo"(MACEDO, 2004, p.310). O autor chega a desautorizar a máxima antiga devido a constatações acerca das histórias excêntricas escutadas a respeito de um bispo local, que impunha suas vontades de modo a converter fiéis ao santo de sua adoração.

Uma das características peculiares desta coletânea de crônicas é o diálogo constante com o leitor, ou melhor, com o companheiro de passeio para o qual se dirige nosso contador de histórias. De acordo com Walter Ong (1958, p. 44), "é essencial que haja um interlocutor virtual: é difícil falar consigo mesmo durante horas consecutivas. $\mathrm{O}$ pensamento apoiado em uma cultura oral está preso à comunicação". Desta forma, compreendemos o recurso utilizado pelo cronista ao narrar fatos e episódios curiosos a respeito dos lugares visitados nesta singular travessia. Ao dialogar e questionar seu acompanhante, MACEDO (2004) recorre a expressões orais que transferem ao seu texto traços de informalidade - típicos dos contos orais:

Fazei de conta que vos achais agora comigo no aprazível terraço do Passeio Público do Rio de Janeiro. [...]

Imaginai tudo isto. Embalar-vos-ei com uma ficção que já tem sido e será mil vezes uma verdade.

Sentemo-nos nestes bancos de mármore e de azulejos. Voltemos as costas para o mar. [...] Cerremos por algum tempo os olhos à majestade das obras de Deus. A hora do crepúsculo é suave, melancólica e propícia aos sonhos do futuro e às recordações do passado. [...] Lembremos antes o passado e, ligados pelo mesmo pensamento, vamos buscar no último quartel do século décimo-oitavo o princípio da história deste jardim público. (MACEDO, 2004, p.88)

BOSI (2003, p. 20) explica que "a fonte oral sugere mais que afirma, caminha em curvas e desvios obrigando a uma interpretação sutil e rigorosa", por isso, os relatos orais são repletos de inúmeras possibilidades de leituras e releituras, exigindo do ouvinte um maior esforço no momento da escuta, já que este deve realizar em sua imaginação um passeio pelas praças e instituições públicas daquela cidade como convida seu contador neste caso. 
A história de frei Fabiano é narrada no passeio pelo convento de Santo Antônio e é repleta de eventos extraordinários que povoam o imaginário popular. MACEDO (2004) instiga-nos sobre a vida deste frei e, à maneira de um verdadeiro contador de histórias, segue sua narrativa fazendo uso de marcas próprias da oralidade:

Conta-se ainda que frei Fabiano, vendo-se perigosamente enfermo, alguns dias antes do seu falecimento, despediu, com suaves consolações, os religiosos que o cercavam e anunciou-lhes o dia e a hora do seu passamento, que exatamente veio a verificar-se, como ele o predissera, no dia 17 de outubro de 1747, pelas 2 horas da tarde. [...] Contam-se coisas extraordinárias observadas no cadáver do caridoso e humilde enfermeiro. (MACEDO, 2004, p.237-8, grifos meus)

Em outro momento, o cronista parece resgatar essas memórias de variadas fontes e utiliza traços próprios do discurso oral intencionando uma comparação com a atualidade em que vive:

Asseveram alguns que os jesuítas, cujo colégio estava situado no monte do Castelo, não viram com bons olhos a vizinhança dos capuchos. [...] Não vos devem admirar essas lutas e oposições a separarem religiosos que deviam pregar e seguir a mesma doutrina. Também a quase totalidade dos nossos homens políticos combate, briga e desatina, bem que um único pensamento esteja no espírito de quase todos, e uma única ambição os devore. Tanto nos padres como nos políticos, a questão é de exclusivismo; [...] (MACEDO, 2004, p.180)

Passagens como esta são comuns ao longo de toda sua narração. A política é alvo do sadismo e críticas constantes por parte de Macedo, que não perde uma oportunidade de "alfinetar" esta categoria tão desprezada e recriminada devido às (desde lá conhecidas) atuações não condizentes para com seu posto.

Outro fato curioso a respeito da imagem do santo protetor do convento de S. Antônio, o qual se encontra no altar-mor do mesmo, é relatado por MACEDO (2004) partindo de registros da memória popular:

Começo pela tradição.

Aquela imagem de S. Antônio é obra de um dos frades da ordem. Trabalhava nela esse religioso com fervor e devoção, e tinha-se saído bem na disposição e execução de todo o corpo da imagem. Chegando, porém, à cabeça, não pôde ajustar ao corpo uma só das muitas que teve de ir fazendo, porque, apesar de todo o seu cuidado e empenho, umas cabeças excediam e as outras não chegavam à medida.

Se a imagem continuava sem cabeça, o frade perdia a própria, porque não podia explicar o motivo da sua súbita e desastrada imperícia. [...]

Mas uma noite, e já bem tarde, soa inesperadamente a campainha da portaria. [...] abre-se a porta e ninguém se apresenta. Olha-se em torno e não vê pessoa alguma. Mas quem o pensaria? Encontra-se depositada no chão uma cabeça de S. Antônio! [...]

A notícia do extraordinário caso espalha-se logo pelo mosteiro. [...] A cabeça do santo é levada ao corpo da imagem, que já estava pronto, serve perfeitamente, e como se de propósito, tivesse sido feita para ele.

Mas de quem e donde viera a cabeça do santo? Nunca se pôde resolver este problema, e as antigas tradições fazem supor que os franciscanos a consideraram obra sobrenatural, executada por mãos sobrenaturais. (MACEDO, 2004, p.185-6) 
BASTIDE (2006) afirma que novos cultos são criados debaixo dos nossos olhos e que isso é parte da essência humana. Desta maneira, nos damos conta que superstições, culto das relíquias, veneração religiosa são necessidades intrínsecas à natureza de todo ser humano. Nessa pequena história, o cronista afirma terem os franciscanos creditado aquela façanha a poderes sobrenaturais, retornando assim à característica singular que possuímos de criar e inventar mitos.

Por meio destas marcas próprias do discurso oral, podemos ratificar que a oralidade está sim presente nas crônicas deste autor. Ao reproduzir em seu texto ditados populares, histórias das mais variadas resgatadas do imaginário popular, ou não seguir uma ordem ou sistema linear em seu relato, bem como ao possuir um interlocutor real (neste caso seu acompanhante de passeio), temos os indícios mais que suficientes para assegurar a qualidade de contador de histórias de Joaquim Manuel de Macedo nesta obra.

\section{A preocupação com a verdade narrada}

A importância dada às fontes das quais o cronista extraiu suas belas histórias acerca das instituições e monumentos públicos do Rio de Janeiro é fato. Em seu livro de crônicas percebemos que, uma vez mais, a verdade está associada à escrita em detrimento das fontes orais, fontes estas igualmente ricas se não mais que aquela, pois são constituídas, em sua essência, da memória coletiva de um povo.

Ao passear pelo Palácio Imperial daquela cidade, MACEDO (2004) refere-se às fontes pesquisadas dando maior credibilidade aos documentos escritos que aos relatos orais:

Irei referir de envolta com alguns fatos registrados nas crônicas do tempo uma ou duas tradições populares. Colhi os primeiros nos livros e memórias que consultei, e as segundas contou-mas um padre velho que morreu há dez anos. Daqueles não é lícito duvidar; a estas pode negar-se crédito sem receio de molestar o padre, que já não tem que ver com as coisas deste mundo. (MACEDO, 2004, p.61)

É visível a supremacia da escrita sobre a oralidade nas palavras do cronista, que levanta suspeitas quanto ao conteúdo das histórias contadas por um padre velho, entretanto, não nos permite questionar os livros de memórias por ele consultados. A este respeito temos as considerações da estudiosa Nei Clara de Lima (2003) que elucidam sobremaneira esta questão:

Extraindo seu pensamento da experiência vivida, a oralidade está sempre muito próxima da situação existencial total e, por isso mesmo, faz parte de um mundo em que a participação e os sentimentos empáticos são os móveis das ações sociais. No entanto, a escrita separa quando desenvolve o pensamento analítico, abstrato, em que o conhecedor e o conhecido 
experimentam um afastamento necessário à objetividade do conhecimento, criando mentes cada vez mais solitárias e independentes do mundo referencial. (LIMA, 2003, p.34, grifos meus)

O fato de estar intimamente próxima do ocorrido faz da narrativa oral detentora de características mais subjetivas e emotivas e, por esta razão, seu conseqüente descrédito ao compararmos com fontes registradas no papel, constituídas de um distanciamento maior entre o fato averbado e seu leitor, reiterando um alto índice de cientificidade no instante da apreensão de seu conteúdo.

Outra maneira de mostrar ao leitor de seu texto a verdade do mesmo é reproduzindo cópias fidedignas de documentos inteiros ou poemas registrados nos diversos ofícios encontrados em suas pesquisas sobre a história de cada local visitado em seu passeio pela cidade carioca.

Ao narrar uma história de amor ocorrida no local onde hoje é o Passeio Público do Rio de Janeiro, MACEDO (2004) reproduz uma canção exatamente como foi proferida no passado, trazendo maior veracidade ao seu périplo:

Em S. Bento deu um'hora

No Colégio deram duas;

Vede que horas são estas

Que eu por ti ando nas ruas!

[...]

Vive sempre a suspirar

Anda sem sossego ter:

Assim mesmo, desta sorte,

À noite te venho ver!" (MACEDO, 2004, p. 97)

A fim de justificar esta transcrição, o autor revela sua preocupação em manter a música tal e qual era no passado, tornando sua história mais verossímil, ao mesmo tempo que critica o esquecimento destas canções:

\begin{abstract}
Não modifiquei em uma única palavra a poesia deste canto; reproduzo-a com todo o seu merecimento especial e com todos os seus defeitos, até mesmo de gramática; sinto não poder também dar uma idéia da música, que aliás, ouvi por vezes em minha infância, e que então me pareceu cheia de doçura e de melancolia.[...] As modinhas e os lundus brasileiros quase que já não existem senão na memória dos antigos; foram banidos dos salões elegantes e com todos os costumes primitivos, [...] (MACEDO, 2004, p.97)
\end{abstract}

Neste trecho, percebemos, sobretudo, a valorização dos mais velhos, os quais são descritos como verdadeiros guardiões do passado e das tradições de um país. Segundo Ecléa Bosi (2003, p. 15), "a memória dos velhos pode ser trabalhada como um mediador entre a nossa geração e as testemunhas do passado. Ela é o intermediário informal da cultura [...]" . Com isso, notamos o precioso lugar ocupado pelos anciãos na sociedade, os quais preservam vivos valores, costumes, crenças, tradições, enfim, a identidade cultural de um povo. Outra 
vez, as características do período romântico fazem-se presentes nas palavras de Macedo ao reivindicar um retorno aos hábitos da cultura tipicamente brasileira - como no caso da música popular -, rechaçados pelos estrangeirismos.

No capítulo destinado à igreja de São Pedro, Macedo reproduz uma escritura oficial que mediava a doação feita pelo piedoso Manoel Vieira dos Santos para a construção de um coro naquela igreja:

A 2 de agosto de 1764, lavrou-se a competente escritura no consistório da igreja de S. Pedro; e como nesse documento se acham especificadas todas as circunstâncias e condições da doação, julgo conveniente reproduzi-lo aqui na sua totalidade, ficando todos os meus companheiros de passeio com a mais completa liberdade de darem um salto por cima da escritura, se não julgarem conveniente lê-la e apreciá-la:

"Fazia doação de hoje para sempre de 42 mil cruzados à dita irmandade, para na igreja dela se estabelecer perpetuamente um coro, que se comporia de cinco capelães, um presidente e quatro meninos de coro, com as cláusulas abaixo declaradas [...]” (MACEDO, 2004, p. 289-290)

O referido documento se faz presente em seu relato como símbolo portador da verdade acerca do fato ocorrido. Estendendo-se por longas seis páginas o conteúdo do ofício, o próprio cronista deixa a critério de seu leitor ler o texto ou desprezá-lo completamente, ratificando a busca pela isenção de suas crônicas.

Outro momento em que o cronista reafirma sua posição de contador de histórias ao longo de seu passeio está no término da narrativa sobre a criação do Passeio Público do Rio de Janeiro. Segundo narrações populares, o Passeio teve origem no sonho que uma bela jovem - admirada pelo vice-rei Luiz de Vasconcelos - teve certo dia, e este, conhecendo seu sonho, em breve, tornou-o realidade:

Esta historieta, tradição ou coisa que o valha, que aliás daria origem um pouco romanesca ao nosso Passeio Público, só poderia ter transpirado por uma indiscrição de mestre Valentim, ou porque Suzana houvesse adivinhado o segredo do gênio do seu sonho de moça. Em qualquer dos casos, acaba, porém, de um modo que não desmente, antes faz honra ao caráter generoso de Luiz de Vasconcelos. Se ainda assim não quiserem aceitar a tradição por lhe faltar seguro fundamento, roguem-me pragas ou critiquem-me à vontade, que nem por isso deixarei de passear. (MACEDO, 2004, p.106)

O descrédito em relação às fontes orais, por não serem portadoras de uma veracidade séria como os materiais históricos escritos, por exemplo, não é um empecilho a Macedo para continuar com seu passeio. Ele diz não se importar com pragas ou críticas outras de seus leitores acerca da procedência de sua narrativa, já que o importante para este cronista é passear.

A preocupação com a verdade é recorrente durante sua narrativa. Muitas vezes, o autor assegura ao seu acompanhante de passeio - o leitor - a veracidade dos fatos narrados através da existência de testemunhas oculares que, ainda vivas, podem perfeitamente confirmar o seu 
relato: "Estou narrando fatos de que ainda há testemunhas presenciais que se podem contar por dezenas, e das quais não haverá uma única que não abone a minha verdade" (MACEDO, 2004, p.329) •

Este livro de crônicas constitui-se basicamente de fatos resgatados da memória coletiva, bem como de fatos extraídos de autêntico material documental escrito. A posição de Macedo frente alguns relatos oriundos da tradição popular é de descrença e dúvida. No entanto, o cronista não deixa de contá-los ao seu público de forma a transmitir ao seu companheiro de viagem a total responsabilidade por aceitá-los como verdade ou não:

Aqui termina a tradição, que julguei não dever desprezar, embora seja eu o primeiro a negarlhe crédito.

Livre da tradição popular, que perturba um pouco ou mesmo muito a verdade da história, prossigo desafrontado na fiel narração dos fatos. [...]

Talvez alguém haja que me lance em rosto o haver misturado com a narração de fatos autenticados nas nossas memórias históricas duas tradições populares, que, aliás, se reduzem a uma única, e que evidentemente pecam por inverossímeis e por falta de fundamento. (MACEDO, 2004, p. 71-72)

É perceptível a incredulidade de nosso contador neste instante de sua narrativa frente à tradição popular. Talvez pelo fato de existirem duas versões acerca da mesma história, MACEDO (2004) levanta suspeitas quanto à autenticidade dos relatos orais a ele contados e, por isso, desconfia da verossimilhança dos mesmos.

Além da tradição popular, o cronista traz histórias registradas em livros e compêndios a fim de enriquecer seu passeio, revelando assim seu empenho e pesquisa a respeito da construção dos edifícios e instituições do Rio de Janeiro, bem como das pessoas que neles habitaram:

[...] vou responder, contando a história de frei Fabiano, como aliás já vos tinha prometido algures.

É a lenda de um santo que me cumpre repetir, e fa-lo-ei, reproduzindo fielmente o que se encontra em livros e manuscritos do arquivo do convento.

Achar-se-ão nesta história belos exemplos da sublime virtude da caridade, e além deles, prodígios que a fé pode receber, e sobre os quais não se deve emitir opinião alguma.

$\mathrm{Eu}$ não discuto. Limito-me a relatar com verdade o que li em papéis que me foram obsequiosamente confiados. (MACEDO, 2004, p. 235)

Novamente, a preocupação com a fidedignidade de suas fontes é visível em seu texto. A veracidade é, a cada instante, reafirmada pelo autor, ao mesmo tempo em que, aponta a origem de cada nova história por ele relatada.

A partir de fatos históricos costurados a relatos provenientes da memória social, foi possível reconstruirmos algumas imagens da cidade do Rio de Janeiro do século XIX, bem como conhecer o imaginário popular daquele período. Conforme o estudo de ROCHA e ECKERT (2005), 
[...] a Cidade moderna revela a frágil condição humana ao apontar para a impossibilidade de os povos e culturas perpetuarem-se no tempo e no espaço sem atribuir, ao ato de narrar, o nobre lugar de construção do conhecimento de si a partir do testemunho legado pelo Outro, pois a vida urbana situa todos nós nas experiências tecidas por memórias compartilhadas. (ROCHA e ECKERT, 2005, p.55, grifos meus)

Através de lendas e crenças próprias da tradição carioca, foi possível lançar um outro olhar sobre as ruas da cidade, os monumentos históricos, as igrejas e conventos, enfim, sobre a tradição popular que permeia a capital imperial, revivida de maneira exemplar por Macedo neste passeio.

A forma escolhida pelo autor no instante de narrar - à sua maneira - as singularidades acerca do patrimônio histórico de sua cidade, fazem de Macedo um típico contador de histórias, pois utiliza as fontes orais em seu périplo potencializando seus pontos positivos com a finalidade de prender seu leitor ao longo de sua marcha pela capital.

As marcas de oralidade e as constantes conversas com seus companheiros de passeio trazem um caráter informal ao seu texto e, concomitantemente, uma sensação de proximidade entre o contador e o ouvinte, estreitando, assim, os laços de comunicação entre ambos.

Apesar de percebemos uma maior credibilidade atribuída aos acontecimentos devidamente registrados e documentados através das palavras deste contador, o mesmo não deixa de preencher a história de cada edifício, instituição ou estabelecimento da cidade com narrações originárias da tradição popular. Sua vocação de escritor não se deixa apagar, já que o cronista parece saber que estes relatos e narrações repletos de imaginação e fantasia tornam sua história mais prazerosa e atrativa ao leitor, opondo-se à pacata condição de ser um mero manual de história daquela cidade.

\section{Referências}

BASTIDE, Roger. O homem essa máquina de fabricar deuses. In: $O$ sagrado selvagem e outros ensaios. São Paulo: Cia das Letras, 2006.

BOSI, Ecléa. O tempo vivo da memória: ensaio de psicologia social. São Paulo: Ateliê, 2003.

LIMA, Nei Clara de. Narrativas orais: uma poética da vida social. Brasília: Editora Universidade de Brasília, 2003.

MACEDO, Joaquim M. Um passeio pela cidade do Rio de Janeiro. São Paulo: Ed. Planeta do Brasil, 2004. v.1. 
ONG, Walter. Sobre a psicodinâmica da oralidade. In: Oralidade e cultura escrita: a reorganização da palavra. Campinas: Pepinos, 1958.

PLATÃO. Fedro. In: Diálogos. Trad. de Jorge Paleikat. Rio de Janeiro: Tecnoprint, 1966.

ROCHA, Ana Luiza Carvalho \& ECKERT, Cornelia. O tempo e a cidade. Porto Alegre: Ed. da UFRGS, 2005. 